5 Kimmelstiel, P., et al., American fournal of Medicine, 1961, 30, 589.

6 Schechter, H., Leonard, C. D., and Scribner, B. H., fournal of the American Medical Association, 1971, 216, 514.

${ }^{7}$ Branch, R. A., et al., British Medical fournal, 1971, 1, 249.

8 Pendreigh, D. M., et al., Lancet, 1972, 1, 304.

$\checkmark$ McGeown, M. G., Lancet, 1972, 1, 307.

10 Nordenfelt, O., Acta Medica Scandinavia, 1972, 191, 11.

11 Pindborg, T., et al., Scandinavian fournal of Urology and Nephrology, $1973,7,196$.

12 Gault, M. H., and Dossetor, J. B., New England Fournal of Medicine, 1966, 275,813 .

13 Lowrie, E. G., et al., New England fournal of Medicine, 1973, 288, 863.

14 Clunie, G. J. A., et al., Medical fournal of Australia, 1971, 2, 403.

15 Doak, P. B., et al., New Zealand Medical fournal, 1971, 73, 117.

${ }^{16}$ Rao, M. M. et al., Medical fournal of Australia, 1972, 1, 209.

17 Sheil, A. G. R., et al., Medical fournal of Australia, 1972, 1, 205

${ }^{18}$ Heale, W. F., et al., Australian and New Zealand fournal of Medicine, $1973,3,330$.

19 Jeremy, D., et al., Australian and New Zealand fournal of Medicine, 1973, 3, 436.

20 Bauer, G. E., Australian and New Zealand fournal of Medicine, 1972, 1, 21.

21 Blackman, J. E., et al., British Medical fournal, 1967, 2, 800.

21 Blackman, J. E., et al., British Medical fournal, 1967, 2, 800.

${ }_{23}^{22}$ Dawborn, J. K., et al., Quarterly Fournal of Medicine, 1966, 35, 69. 2.280.

${ }_{24}$ Gault, M. H., et al., Annals of Internal Medicine, 1968, 68, 906.

24 Gault, M. H., et al., Annals of Internal Medicine, 1968,

26 Kincaid-Smith, P., Nanra, R. S., and Fairley, K. F., In Renal Infection and Renal Scarring, ed. P. Kincaid-Smith and K. F. Fairley, p. 358. Melbourne, Mercedes, 1970.

${ }^{27}$ Steele, T. W., and Edwards, K. D. G., Medical Fournal of Australia, 1971,

${ }^{28}$ Murray, R. M., Lawson, D. H., and Linton, A. L., British Medical fournal, 1971, 1, 479 .

29 Australia, Commonwealth Bureau of Census and Statistics, Causes of Death, Bulletin No. 4. Canberra, 1966.

${ }^{30}$ Australia, Commonwealth Bureau of Census and Statistics. Causes of Death, Bulletin No. 5. Canberra, 1967.

31 Lindvall, N., Acta Radiologica, 1960, Suppl. 192.

32 Milojćć, B., Lancet, 1960, 1, 244.

33 Danilovic, V., and Stojimirović, B., In The Balkan Nephropathy, ed. G. E. W. Wolstenholme and Julie Knight, p. 44. London, Churchill, 1967.

${ }^{34}$ Emmerson, B. T., Kidney International, 1973, 4, 1.

${ }^{35}$ Lyon, R. P., Marshall, S., and Tanagho, E. A., Fournal of Urology, 1969, 102,504 .

${ }^{36}$ Hodson, C. J., Proceedings of the Royal Society of Medicine, 1959, 52, 669.

37 Talbott, J. H., and Terplan, K. L., Medicine, 1960, 39, 405

38 .

39 Kincaid-Smith, P., McMichael, J., and Murphy, E. A., Quarterly fournal of Medicine, $1958,27,117$.

40 Alport, A. C., British Medical fournal, 1927, 1, 504.

41 Alport, A. C., British Medical fournal, 1927, 1, 504.

42 Merkoff, G. T., New England fournal of Medicine, 1967, 277, 79. Bacteriology, 1967, 93, 65 .

\title{
Surgery of Violence
}

\section{Disaster Procedures}

\section{W. H. RUTHERFORD}

\section{British Medical fournal, 1975, 1, 443-445}

One of the effects of bomb blast is that patients often arrive simultaneously in large numbers. This kind of multiple accident has been given many names, but recently the word disaster has become the generally accepted one. Bombing itself is a symptom of an illness in the community, and is unlikely to be an isolated incident. Over a three-year period the Royal Victoria Hospital, Belfast, had to receive multiple casualties from bombs on 48 occasions. (There were also 15 occasions when street rioting gave rise to a disaster situation). The repeated use of the hospital's disaster plan gave us unusual opportunities to assess the value of its provisions. At least we were delivered from the first great difficulty in disaster planning, which is the difficulty in believing that the disaster will ever really happen.

The second difficulty arises from the multidisciplinary nature of disaster planning. Within the hospital it is a co-operative venture co-ordinating medical, nursing, and administrative services. Outside hospital, as well as medical services, it involves police, ambulance, and fire services, and possibly welfare services and some voluntary bodies. Multidisciplinary agreement is always more difficult to achieve than agreement between people inside any one discipline.

\section{Disaster Planning at Hospital : Two Basic Principles}

\section{A COMMAND STRUCTURE}

Disasters are totally unpredictable in size, in the types of injuries, and in the proportions of minor and major injuries. The number of staff on duty at the time varies, and a dramatic disaster will bring many members of staff to hospital without being called. It is therefore impossible to detail in advance what resources should be called on. One should therefore quickly set

\footnotetext{
Accident and Emergency Department, Royal Victoria Hospital, Belfast

W. H. RUTHERFORD, F.R.c.s., Consultant Casualty Surgeon
}

up a command structure whose responsibility is to monitor both the influx of casualties and the arrival of volunteer staff. The command team will direct people where to work and mobilize additional staff and other resources as required. This command structure will consist of the senior officers in the medical, nursing, and administrative fields, with the consultant of the casualty department.

\section{VALUE OF STICKING TO THE DAILY ROUTINE}

Working under stress, people tend without thinking to do the same thing that they do every day. If the disaster plan is drawn up with this in mind, it is likely to go smoothly. The more often procedures depart from the daily routine, the more mistakes are likely. For example labels tied to the wrists of patients are likely to cause more confusion than help unless those using them are accustomed to such a system in their daily work.

\section{Some Important Aspects in Hospital}

1. TRIAGE

This word means sorting out. It was used for the sorting out of battle casualties at forward clearing stations and is now often applied to disasters. Within hospital there are three points at which triage occurs.

On arrival the patients are sorted so that the space and facilities of the casualty are best used. The worst cases will go to the resuscitation room, the next worst to adjacent cubicles, and the less serious a case appears the farther from the resuscitation room will he be placed. Patients with mild injuries do not object if three or four of them are asked to share a cubicle normally used for one. A weeping room for the emotionally shocked but uninjured can be well away from the main stream of patients. An area for suturing wounds outside the department is also useful in allowing a more rapid turnover.

The actual placement of patients in cubicles can be done very well by the casualty sister. The casualty consultant will sort his resources of staff, allocating specific doctors to patients or 
to areas of the department. To a considerable extent the sister and consultant will overlap in these duties, and both will need to be available for answering the questions of those not regularly working in the department.

We are very fortunate to have a department with 20 cubicles, and an adjacent fracture clinic with a further 15 cubicles. On the upper floors of the same building are all the other outpatient clinics. Throughout the building a standard trolley is used in all cubicles. The value of the extensive cubicle space on the ground floor and the great number of trolleys has been incalculable.

The $x$-ray department is inclined to be a bottleneck. It is useful for a senior doctor to screen requests. Some can be cancelled, some delayed for 24 hours, and the remainder arranged in order of priority.

Priorities for the operating theatre will be decided by a senior consultant surgeon. Providing him with correct lists of all admitted patients with rough details of their injuries is an important aspect of the documentation problem.

\section{DOCUMENTATION}

The importance of documentation cannot be overstated. Safe transfusion depends on it. The clinical record made on admission is likely to be the only preoperative record. These situations often result in public inquiries and in litigation. All of these facets require good records. I will describe in detail how our own system works, and then suggest how to achieve a similar result where the same types of papers are not available in daily use.

The issuing of case papers is one place where we alter our normal routine. Instead of sending patients or relatives to a receptionist we place the patients in suitable cubicles, and one or two receptionists walk round from cubicle to cubicle with armfuls of case papers, issuing papers to patients as they find them.

Duplicating papers: Our routine case record is five sheets thick, made on self-copying paper. This is very useful in a disaster. The receptionist leaves the top two copies with the patient and takes the lower copies to the desk. From these another clerk can start to make the basic list of people who have arrived in hospital. All clinical notes, $x$-ray requests, and records of treatments and investigations are written on the two copies which are with the patient.

For the collection of information it is helpful during a disaster if it can be arranged that only one way remains for all patients to get out of the casualty department. When they go to theatre or ward, or to a suturing area, one copy of their paper is handed in to the desk and the other travels with them. If they are being discharged home, both are collected. Efficient collection of papers is very important. It is amazingly easy to lose people, or for their papers to be left lying around cubicles after they have left.

Listing of patients is carried out soon after they arrive. As they leave the casualty department a copy of their record is handed in and information from it is added to the basic list. For all patients a rough diagnosis and the disposal (admission, transfer, discharge, etc.) are entered. For patients who are being admitted it is noted whether their condition is critical, serious, or fair. Lists with these items are made up with fairly few names to each sheet. As a sheet is completed, it is photocopied. The copies are then passed to people responsible for communications and inquiries. In this way it is possible to keep abreast with events almost as they happen. There is great reassurance both for the hospital staff and for the public in knowing that correct information is quickly and accurately available.

$A$ modified system: If the normal documentation does not incorporate duplicated copies, the receptionists, when issuing basic case records, would need to take with them also forms to list the name and case number of each case they issued. If more than one receptionist was doing this, their lists should be amalgamated. If possible, patients going to theatre or ward should have their records photocopied. The photocopy would travel with the patient and the basic record stay at the main documentation centre in the casualty.

\section{THE MEDIA}

Nobody can deny that the public wants to know about a disaster. The dissemination of information is the responsibility of the mass media. Doctors have many worries in a disaster. The last thing they want is an interview. But the story is going to be written and told, and arrangements must be made to see that it is done. Where there is already a good working relationship between doctors and reporters they are likely to co-operate well in a disaster. But if there is mutual suspicion and hostility in daily relationships a disaster will exaggerate this position.

Hospitals are ultimately dependent on the public for finance. Adequate finance is more likely to be forthcoming from a sympathetic public. A disaster is a moment where public interest comes to the hospital. Well-presented information will do the hospital a lot of good.

Newsmen are attracted by the dramatic-the best pictures are the most shocking. Reporters are not noted for being overscrupulous about people's feelings. It is the responsibility of doctors to see that patients or relatives who want to opt out of interviews or photographs can easily do so.

In a disaster from civil disturbance groups of people in society are taking up polarized attitudes. The hospital may be seen as part of the establishment, and therefore prejudiced. The more the hospital can avoid getting involved in the pros and cons of the conflict, the more it will be in a position to be available for the treatment of all.

\section{TWO UNTESTED IDEAS}

As explained before, the most crucial step in disaster management in hospital is the rapid mobilization of what $I$ have called the command structure. The team will have at least four people-a doctor, a nurse, and an administrator in charge of their respective departments, and a consultant for the casualty department. At the beginning of a disaster these four will need to be alerted within minutes, and should be within the hospital in 10-15 minutes. Walkie-talkie sets would have the advantage of almost instant contact through the 24 hours. The hospital should always have people clearly responsible for these four key posts. The walkie-talkie sets would be a concrete reminder of exactly who was on duty. If any officer is to be covered by a deputy, he would hand over his set to his deputy. These officers would find other uses for their sets in their daily work. Alternatively a "bleep" call-up would be satisfactory provided it had a range which could contact the officers at home as well as in hospital.

I have read accounts of disaster rehearsals but have never been in one myself. I am a little suspicious of their value because in a real disaster the main difficulty is the great stress under which one has to work. It is impossible to reproduce this element in a disaster rehearsal. At a disaster site a rehearsal may be of help in sorting out some problems of logistics. But inside hospital I am not sure that its benefits justify the disturbance to the treatment of real patients.

Many features of a hospital's disaster drill can be rehearsed without casualties. The most important of these is the original call-up of the command structure. This could be rehearsed once a month without disturbance to anybody. Other parts of the plan which could be similarly rehearsed are the preparation of lists of patients as for a disaster, and the re-routing of patients so that they left the department by one door only. Both of these could be practised at a busy time on any normal day. Similarly the documentation of ward patients as fit for discharge could be practised any time, as could the setting up of a pre-transfer ward in the gymnasium. If sections of the plan were regularly 
rehearsed in this way, minds would be kept alert to the possibility of disaster, and under the pressure of a real event routines would flow smoothly.

\section{Disaster Organization at the Site: \\ Forces of Chaos and Forces of Order}

One of the outstanding factors at the site is the highly charged emotional atmosphere. One emotion which may affect many people is a sense of terror. People become incapable of speech or of deciding the simplest detail of what they ought to do. Another emotion is curiosity: the disaster acts as an enormous human magnet sucking in crowds of people. A more positive emotion is a deep concern for the injured, the realization that they may be in great danger and needing to be taken rapidly to hospital. Before there are shovels, people will lift masonry away brick by brick. Before there are excavators or lorries, people will pass rubble from hand to hand.

The admixture of all this emotion and the resulting activity results in confusion on a massive scale. Into this highly charged amateur situation members of the services arrive as professionals. It is the job of policemen, firemen, and ambulancemen to think coolly, to use common sense, to withstand the negative aspects of the crowd's response and to harness the positive.

\section{Medical Role at the Site}

RAPID TRANSPORT OF PATIENTS TO HOSPITAL

In all but one or two disasters we have been involved in no doctor has been sent to the site either from the hospital or from the area board. The ambulancemen have themselves extracted the injured patients with the help of firemen, police, and soldiers. The bombings have all occurred within a four-mile $(6-\mathrm{km})$ radius of the hospital. The emphasis has been on rapid movement of patients to hospital, and doctors have been concentrated ready to receive and treat patients in hospital. No resuscitation was carried out on site, and I do not know of any case where this affected the outcome unfavourably. No doubt there may be rural disasters and even other types of urban disasters where resuscitation on site might be advantageous. But in urban bombing we have found that rapid evacuation to hospital is a satisfactory system.

It is true that this policy results in minor casualties often arriving first in hospital. Whenever a seriously injured victim was extracted, he was always given priority for transport. But before the serious cases could be extracted, no merit was seen in keeping crowds of people with minor injuries waiting around at the site.

\section{ON-SITE MEDICAL OFFICER}

Ideally I think there should be a senior medical officer at the site. His presence would relieve considerable anxiety from the police, fire, and ambulance officers, and enable them to do their own work more efficiently. His reports to hospitals on the extent of the disaster and possible numbers of casualties would be of great help in hospital. He might be of some help in sorting out which hospitals casualties should be taken to. This matter, however, can probably be best decided in the offices of the ambulance control or emergency bed service.

\section{MEDICAL TEAMS}

Where there is an emergency rescue service operating from a hospital for road traffic and other accidents, its services would be welcome at the disaster site. Doctors and nurses with no previous experience of this work are likely to be a hindrance rather than a help. In a rural setting a general-practice rescue service would be especially welcome, as with longer ambulance journeys the value of resuscitation for the badly injured will greatly increase.

\section{Conclusion}

Planning for disaster still presents many difficulties. The question arises of who is ultimately responsible to see that proper plans exist in an adequate state of readiness, covering the whole country and all the services needed. It is a question which is so far unanswered.

\title{
Contemporary Themes
}

\section{Accident and Emergency Services in Russia}

\author{
J. F. HINDLE, L. W. PLEWES, R. G. TAYLOR
}

British Medical fournal, 1975, 1, 445-447

In the Spring of 1974 we were privileged to visit the U.S.S.R. as guests of the Russian Ministry of Health to see their accident and orthopaedic services. Our tour included Moscow, Lenin-

Luton and Dunstable Hospital, Luton, Bedfordshire LU4 OD2 J. F. HINDLE, M.B., F.R.C.S., Consultant Surgeon, Accident Service

Nuffield Orthopaedic Centre, Radclifie Infirmary, Oxford

R. G. TAYLOR, M.CH., F.R.C.s., Consultant Orthopaedic Surgeon

grad, Kiev, Tbilisi, and Kutaisi, and we found much of interest. In every orthopaedic department we saw examples of the unique Russian method of treating complicated limb fractures by the compression distraction apparatus. The results were impressive, especially when used in the management of an infected pseudarthrosis of the tibia. At the famous Sklifosovsky Institute (Moscow), where Professor Yudin first used cadaver blood for transfusion, we spent some time in the special department where cadaver material is collected. Half of the blood is put in the plasma stores and the other half in the transfusion bank. This department supplies blood to all Moscow's hospitals. All tissues useful for transplantation are removed and stored: bone, cartilage, tendon, fascia, cornea, kidney, and liver. Surgical and 